\title{
Overcoming the liability of distance? An exploratory study of the associations between social networks, sense of community and spatial colocation
}

\author{
Felichism Kabo
}

Institute for Social Research, University of Michigan, Ann Arbor, Michigan, USA

Overcoming the liability of distance

Received 16 October 2020 Revised 28 April 2021

17 August 2021 26 October 2021

Accepted 27 October 2021

\begin{abstract}
Purpose - This study aims to examine the associations of social networks with the sense of community (SOC) construct and spatial colocation or having an office. The study site was an institute for health-care policy research formed in 2011 by bringing together scientists from more than 20 different university units. Only $30 \%$ of the scientists were had an office or physical presence at the institute. Therefore, the institute was an ideal site to examine whether SOC was correlated with different dimensions of network position connectedness, reachability and brokerage - even when the authors account for the lack of spatial colocation for the off-site scientists.
\end{abstract}

Design/methodology/approach - A two-part (sociometric and workplace) internet survey instrument was administered in 2014 to the institute's population of 411 individuals. The sociometric data were used to create an undirected interaction network and the following dependent variables (DVs) or network centralities: normalized degree to measure connectedness; average reciprocal distance to capture reachability; and normalized betweenness to proxy brokerage. Separate node-level network regressions were then run with random permutations $(N=10,000)$ and listwise deletion for each of the DVs with SOC and spatial colocation as the independent variables, and variables that controlled for gender, organizational affiliation and job category.

Findings - SOC and spatial colocation are both positively and significantly correlated with network connectedness and reachability. The results suggest that both SOC and spatial colocation have a larger impact on reachability than connectedness. However, neither SOC nor spatial colocation are significantly associated with network brokerage. Finally, the findings show that SOC and spatial colocation are more reliable predictors of network connectedness and reachability than are key individual- and unit-level control variables, specifically the individual's sex, job category and organizational affiliation. The controls were not significantly associated with any of the three network centralities, namely, connectedness, reachability and brokerage.

Originality/value - This exploratory study used social network analysis and node-level network regressions to examine the associations from SOC and spatial colocation to dimensions of network position. SOC is positively and significantly associated with network connectedness and reachability, suggesting that SOC is an important consideration when individuals are disadvantaged from the absence of spatial colocation. The findings have implications for work in the context of the COVID-19 pandemic as they imply that

(C) Felichism Kabo. Published by Emerald Publishing Limited. This article is published under the Creative Commons Attribution (CC BY 4.0) licence. Anyone may reproduce, distribute, translate and create derivative works of this article (for both commercial and non-commercial purposes), subject to full attribution to the original publication and authors. The full terms of this licence may be seen at http://creativecommons.org/licences/by/4.0/legalcode

The author would like to thank the HIPRI director and his staff for their support and encouragement. The director especially went out of his way to facilitate the study and data collection without which this paper would not have been possible.

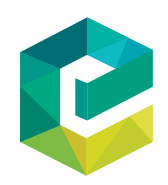

Journal of Corporate Real Estate Vol. 24 No. 4,2022 pp. $273-289$ Emerald Publishing Limited 1463-001X 
JCRE 24,4

interventions based on the SOC construct could potentially lessen the negative effects of remote work on workplace social networks due to factors such as the reduction of social contacts.

Keywords Social network analysis, Sense of community, Proximity/colocation, Connectedness, Reachability, Brokerage

Paper type Research paper

\section{4}

\section{Introduction}

The physical workplace has long been understood as the stage upon which social encounters and interactions in organizations translate to important outcomes related to communication, collaboration and team science (Olson and Olson, 2000; Olson et al., 2002; Serrato and Wineman, 1999; Wineman et al., 2009; Peponis et al., 2007). Spatial proximity is a key driver of the chance or serendipitous encounters that are essential to organizational innovation (Kabo et al., 2014; Kabo et al., 2015; Lee et al., 2010; Baumann et al., 2012; Baumann and Boutellier, 2012). The COVID-19 pandemic has made it difficult if not impossible for employees to have face-to-face interactions in the physical workplace. At the same time, there has been a dramatic increase in the use of technology-mediated communication platforms, such as Zoom and Skype especially starting in early 2020 when many governments introduced workplace shutdowns as a means of controlling the coronavirus (Gilbert, 2020; Sherr, 2020). It is still unclear what these trends mean for organizations as the importance of communications between employees is not diminished by the pandemic, and as there is no evidence that we no longer need face-to-face interactions in the workplace with respect to collaboration, team science and innovation. This paper presents the results of a study of the relations between spatial colocation and sense of community (SOC), and three different dimensions of network position or centrality corresponding to an individual's connectedness to others, reachability to and from others across the network and ability to stand in brokerage between others in the network.

There is some evidence going back two decades that technology could mitigate some of the liabilities of collaborating over distance by creating a sense of presence or "being there" (Cummings and Bailenson, 2016; Schroeder et al., 2001). The concept of the collaboratory, a portmanteau of the words "collaboration" and "laboratory" to mean a "laboratory without walls" characterized by internet-mediated science performed by geographically distributed collaborators (Teasley and Wolinsky, 2001; Wulf, 1993; National Research Council, 1993; Lederberg and Uncapher, 1989), appears tailor-made for work in the context of the pandemic. And yet, despite advances in information technology and mediated communication, distance still matters and colocation affords aspects of face-to-face human interactions that are neither logically nor pragmatically replicable by technology, (Olson and Olson, 2000; Olson et al., 2002; Nardi and Whittaker, 2002). Further, there is evidence of a complementary rather than substitutionary relationship between technology-mediated communication and face-to-face interaction (Calabrese et al., 2011). Finally, recent accounts of work under COVID-19 suggest that technology-mediated communication is cognitively more taxing than face-to-face interaction, enough to induce the type of stress and exhaustion being creatively referred to as "Zoom fatigue" (Wiederhold, 2020; Morris, 2020; Fosslien and Duffy, 2020; Cranford, 2020).

It is unlikely that the question of the importance of face-to-face interaction in the workplace is going to be resolved any time soon given evidence on the positive and negative aspects of technology-mediated communication. This exploratory study, rather than jumping into that debate, focuses on the face-to-face and group dynamics at the workplace that are associated with organizational social networks. As previously mentioned, social 
networks matter for collaboration and innovation, and spatial proximity plays a positive role in the formation and maintenance of social ties and networks (Kabo et al., 2014; Wineman et al., 2009; Sailer and McCulloh, 2012; Wineman et al., 2014; Kabo et al., 2015). The role of the spatial environment in the formation of social relations works across multiple levels, such as buildings, neighborhoods and organizations (Small and Adler, 2019). This study examines the effect of the "sense of community" (SOC) construct and spatial colocation (having an office) on the network positions of the members of a health-care policy research institute where spatial proximity or colocation is only possible for some and not all the scientists.

\section{Social network analysis (SNA)}

A social network is a structure that comprises of a set of actors, and the sets of relations that connect some or all the actors. Even for the same set of actors, each type of relation maps onto a different network (Knoke and Yang, 2008b). Social network theory (SNT) addresses the fundamental problem of social order by offering mechanisms that explain how individuals combine to create groups and societies (Borgatti et al., 2009). SNT provides explanations that advance the study of social relationships among actors, which is at the core of the social sciences (Borgatti et al., 2009; Breiger, 2004). SNA is the disciplined inquiry into the patterns of relations among actors where the network consists of nodes representing the actors -which can be abstract or material entities, such as ideas, web pages, individuals, teams and organizations- and ties representing the relationships among the actors (Breiger, 2004; Davis, 2007; Borgatti and Foster, 2003; Borgatti et al., 2013). Networks can be examined at different levels of analysis, the actor or node, the dyad (pair of actors or nodes) and the overall group or network (Borgatti et al., 2009; Borgatti and Foster, 2003). This study focuses on actor- or node-level analysis. There are excellent resources that the reader can consult for more on network levels of analysis (Mizruchi and Marquis, 2006; Borgatti et al., 2013). The node-level analysis enables us to address questions such as whether individuals that are more central in the organization's interaction network are more likely to have higher performance reviews. This study specifically focuses on three node-level dimensions of network position that are examined in relation to spatial colocation or having an office and SOC.

Connectedness is related to the idea that the social capital that an individual has is a function of their connections to those around them or in their immediate environment (Hanneman and Riddle, 2014). Individuals that have more connections are more likely to have more contact with others and to be exposed to more (and more diverse) information (Hanneman and Riddle, 2005a). Not only are highly connected individuals more likely to be influenced by others but also they themselves may be more influential (Hanneman and Riddle, 2005a). Reachability captures the ease with which an individual can rapidly transmit something to many others in the network and, conversely, the risk of rapidly catching something from many others in the network (Borgatti et al., 2013). Individuals with high reachability can reach and be reached by most members of a network with little effort as they are more likely to be connected to individuals that have nonoverlapping connections (Hanneman and Riddle, 2005a). Brokerage is when an individual is advantageously positioned between others such that they can use this structural advantage facilitate or control access to resources and opportunities to their benefit (Burt, 1992). By being positioned as intermediaries between others, individuals with high brokerage, such as those that connect different groups, are more likely to have higher social capital than those with low or no brokerage (Burt, 2004; Burt, 2000).
Overcoming the liability of distance 
JCRE 24,4

\section{Sense of community (SOC)}

The SOC construct has been associated with important outcomes in studies set in diverse contexts, including neighborhoods and the built environment (Sengupta et al., 2013; Zhang and Zhang, 2017; Wood et al., 2010). Sarason (1974, p. 1) defined SOC as the "sense that one was part of readily supportive network of relationships upon which one could depend." McMillan and Chavis (1986) identified four dimensions to SOC; membership or a feeling of belonging, influence or a reciprocal sense of mattering between the group and its members, integration of needs or the feeling that one's needs will be met through membership in the group, and shared emotional connection or the past and future shared histories, places and experiences among members. SOC has more recently been emphasized as a core cognitive or psychological component of the social capital construct that is related both to trust in one's neighbors and the social support from one's community (Perkins and Long, 2002; Zhang and Zhang, 2017; Rung et al., 2017). In highlighting the relation between SOC and social capital, these more recent studies reconnect the SOC concept to social ties and networks in line with Sarason's classical definition.

Social capital, the actual or potential resources inherent in the structure of social relations between and among actors (or networks), is both a function of social structure and a metaphor about competitive advantages for certain individuals or groups (Portes, 1998; Burt, 2000; Lin, 2001; Coleman, 1988). At the most basic level, the concept of social capital captures the value and importance of connections (Borgatti and Foster, 2003). At the individual-level of analysis, social capital focuses on the relations that an actor maintains with other actors and thus has a lot of similarity or overlap with SOC to the extent that both constructs emphasize the benefits that accrue to actors due to their membership in specific social structures (Boyd and Nowell, 2013). However, the two constructs differ in that while social capital at the collective level focuses on how the attributes of the relations among a set of actors impact the performance of the collective, SOC is inherently analyzed at the individual level (Boyd and Nowell, 2013). Where SOC is the perceived advantage of membership in the group and hence a psychological phenomenon, social capital is the actual advantage conferred by the group's social structure and hence a sociological phenomenon (Boyd and Nowell, 2013).

\section{Spatial colocation or proximity}

Individuals are considered to have spatial proximity or colocation when they are, in a binary sense, co-present, and thus not distant from one another. At its most basic, spatial proximity is conceptualized as the inverse of the absolute metric distance between individuals, where the shorter the distance the more proximate the individuals are. The issue of "how far is too far" is context-specific, contingent on the level of analysis. For example, at the regional level, individuals may be collocated if they are in the same city. At the organizational level, spatial proximity or colocation is usually defined with respect to the workplace, which may consist of one or more contiguous buildings in a geographically bounded space, such as a complex and campus. At the building level, given the precipitous decay in the probability of communication after $50 \mathrm{~m}$ or 164 feet, one may plausibly consider individuals that are 200 feet apart to not be spatially proximate, while those that are less than 100 feet apart could be considered to enjoy colocation (Allen and Fustfeld, 1975; Allen, 1977, 2007). Note that in most studies "proximity" typically refers to spatial or geographical proximity even other dimensions of proximity exist (Knoben and Oerlemans, 2006). In this study, any reference to "proximity" should be strictly interpreted as spatial proximity. More specifically, the study examines organizational-level proximity or colocation, which is defined as whether individuals have offices or workspaces in the organization's building(s). This dichotomous 
conceptualization of proximity is different from other constructs that might be used in proximity studies at other levels of analysis, such as continuous distance at the building level of analysis.

Across multiple organizational settings and workplace arrangements, proximity is significantly associated with important organizational processes and outcomes including communication (Allen and Henn, 2007), movement (Penn et al., 1999; Appel-Meulenbroek, 2009), collaboration (Lee et al., 2010; Leone Sciabolazza et al., 2017; Brown, 2008), team science (Olson and Olson, 2000; Hoegl and Proserpio, 2004) and innovation (Wineman et al., 2009; Baumann et al., 2012; Hoegl and Proserpio, 2004). For example, in scientific settings, proximity is positively correlated not just with the probability of collaboration in scientist dyads but it is also is associated with the likelihood and magnitude of the success of the collaboration (Kabo et al., 2014). Also, in a study of university research centers, proximity was found to be correlated with higher rates of the face-to-face consultations that are critical to the innovation process (Toker and Gray, 2008). The focus on organizational-level colocation is based on the premise that whether individuals are spatially collocated maps onto organizational behaviors and culture (Rashid, 2013). Organizational culture sets the stage for acceptable workplace behaviors, which are, in turn, related to individuals' positions in the organization's social network (Peponis et al., 2007).

\section{Methods}

\section{Study population}

The study population was the members $(N=411)$ of a new health-care innovation and policy research institute (HIPRI) as of 2014. HIPRI is affiliated with a top-ranked research university (RU) and was formed in 2011 by bringing together scientists from more than 20 different academic units that were in buildings that were on one of three RU campuses, or elsewhere in the medium-sized city in the Midwestern USA in which RU is located. As of when the study was initiated in 2014, about $30 \%$ of the study population had an office or other physical presence in one of three HIPRI buildings that are in a large research complex that is on the RU's north campus as illustrated in Figure 1. The location of the three adjoining buildings that HIPRI occupies is also shown on the map.

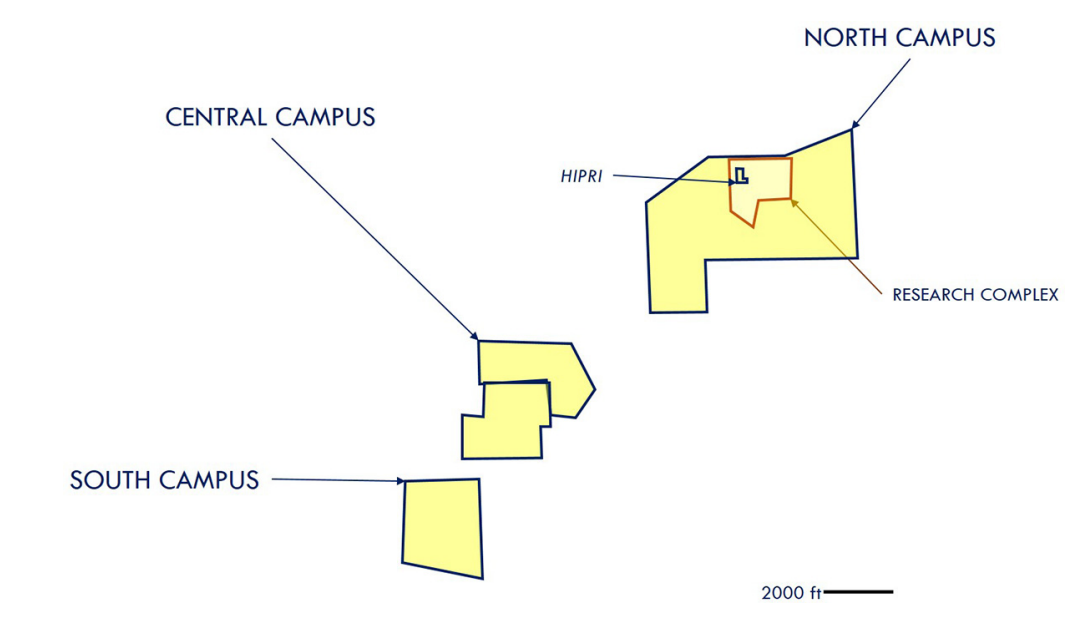

Overcoming the liability of distance

Figure 1.

Schematic map (to scale) of RU's three campuses that indicates the position of HIPRI's three

buildings. Most of HIPRI's population is located on the central campus 
JCRE 24,4

Table 1.

Summary statistics for the HIPRI population $(N=411)$

\section{Data collection}

The HIPRI director's office facilitated the recruitment of participants in the exploratory study. In May 2014, a cover letter and study description were posted on the electronic HIPRI Newsletter. Following that, an e-mail was sent by the director to inform the HIPRI population that the study had been approved by HIPRI and RU's Institutional Review Board. An internetbased survey engine (Qualtrics, 2017) was used to administer a two-part survey in May and June 2014 to the HIPRI population. Part 1 of the survey was a 12-item sociometric instrument that focused on interactions with colleagues, and Part 2 was a 33-item instrument that focused on socio-physical perceptions of the workplace. There were 213 survey respondents in total (or a $52 \%$ response rate) including both partial and full survey completions. Listwise deletion was done for the regressions whereby individuals were retained in the models only if they had complete data across the focal variables both from Parts 1 and 2 of the survey. Tables 1 and 2 display the summary statistics for the HIPRI population while Tables 3 and 4 show the summary statistics for the 130 individuals with full or complete data.

\begin{tabular}{lcccc}
\hline Variable & Mean & SD & Min & Max \\
\hline Has office at HIPRI & 0.304 & 0.461 & 0 & 1 \\
Sex & 0.584 & 0.494 & 0 & 1 \\
Medical school affiliation & 0.601 & 0.490 & 0 & 1 \\
\hline
\end{tabular}

\begin{tabular}{lcc}
\hline Variable & Frequency & Percent $(\%)$ \\
\hline Job category & & \\
0 Assistant Professor/scientist & 99 & 24.09 \\
$1=$ Associate Professor/scientist & 103 & 25.06 \\
$2=$ Full Professor/scientist & 148 & 36.01 \\
3 Fellow/Investigator/Lecturer/other & 61 & 14.84 \\
\hline
\end{tabular}

\section{Table 3.}

Summary statistics (including network centralities and SOC) for the individuals with complete data $(n=130)$

\begin{tabular}{lcccc}
\hline Variable & Mean & SD & Min & Max \\
\hline Normalized degree & 0.066 & 0.058 & 0 & 0.439 \\
ARD & 0.443 & 0.070 & 0 & 0.700 \\
Normalized betweenness & 0.010 & 0.025 & 0 & 0.268 \\
SOC & 16.885 & 3.059 & 0 & 20 \\
Has office at HIPRI & 0.485 & 0.502 & 0 & 1 \\
Sex & 0.623 & 0.486 & 0 & 1 \\
Medical school affiliation & 0.700 & 0.460 & 0 & 1 \\
\hline
\end{tabular}

\section{Table 4.}

Job category frequency table for the individuals with complete data $(n=130)$

Variable
Job category
$0=$ Assistant Professor/scientist
$1=$ Associate Professor/scientist
$2=$ Full Professor/scientist
$3=$ Fellow/Investigator/Lecturer/other

Frequency

Job category

$0=$ Assistant Professor $/$ scientist

36

30

27.69

23.08

45

34.62

19

14.62 
Tests for the equality of proportions between the HIPRI population and the subgroup with complete data showed that the latter had a higher proportion with a HIPRI office $\left(\chi^{2}=\right.$ $17.984, p<0.001)$ and from the medical school $\left(\chi^{2}=7.540, p=0.006\right)$. There were no significant differences in the proportions for $\operatorname{sex}\left(\chi^{2}=0.412, p=0.521\right)$ and job category $\left(\chi^{2}=0.538, p=0.444\right)$.

\section{Social network analysis}

Respondents were asked to fill out the interaction network item from Part 1 of the survey for all scientists in the institute minus the ego [1]. The nature of workplace interaction allowed us to make the case for symmetrizing the network and thus addressing the issue of the data that are missing because of nonresponse (see for example, Stork and Richards, 1992; Huisman and Steglich, 2008). That is if A said that she interacted with B, if B did not respond to the survey, then it can be assumed that $B$ also interacted with $A$. In this way, the interaction network captures most of the study population. Network visualization was done using Netdraw which is a companion software to Ucinet (Borgatti, 2002).

\section{Variables}

Symmetrization was performed on the directed interaction network that is shown in Figure 2 [2]. This created an undirected interaction network that was used to generate three normalized measures of network centrality that are the dependent variables (DVs). Normalization makes possible comparisons of node centrality across networks regardless of network size. Normalized degree is the number of nodes directly connected to a focal node normalized by the maximum number of connections possible for the node. The average reciprocal distance $(\mathrm{ARD})$ is the mean of the inverse distances from the focal node to all other nodes in the network, inversely weighting distances by how far away they are. By valuing shorter over longer paths, this overcomes the limitation of using unweighted distances based on the assumption that far nodes (e.g. four steps away) are the same as near nodes (e.g. one step away). Normalized betweenness is how often a given individual falls on the shortest paths between other pairs of individuals normalized by the maximum possible number of shortest paths. Normalized degree is a local measure of network centrality and is a function of how many other nodes are one step away from the focal node. In this study, normalized degree is used as the proxy for connectedness. ARD and normalized betweenness are global measures of network centrality. Unlike normalized degree which focuses on the focal node's immediate ties, ARD captures the focal node's reach across the entire network or their probability of sending/receiving to/from other nodes in the network (Borgatti et al., 2013). In this study, ARD is used as the measure for reachability. Finally, normalized betweenness captures the number of shortest paths across the entire network that pass through the focal node (Freeman, 1977) in the context of the paths as pipes that channel flows of resources between individuals (Podolny, 2001). In this study, normalized betweenness is used to capture brokerage.

The independent variable (IV) ("Sense of community [SOC]") is a scale that was developed using four items from Part 2 of the survey based on factor analyses for the 10 questions in the section titled "Here are some statements about working with others - how would you respond for your job?" The response options for all 10 questions were on a fivepoint Likert ordinal scale as follows: Disagree, Somewhat Disagree, Neutral, Somewhat Agree and Agree. Factor analyses (with orthogonal rotations of the loading matrix) of the 10 questions in the section showed that the primary item in the scale, there is a "sense of community" in my unit/group/department, loaded strongly onto the first factor as did the following three items:

\section{Overcoming the liability of distance}


JCRE 24,4

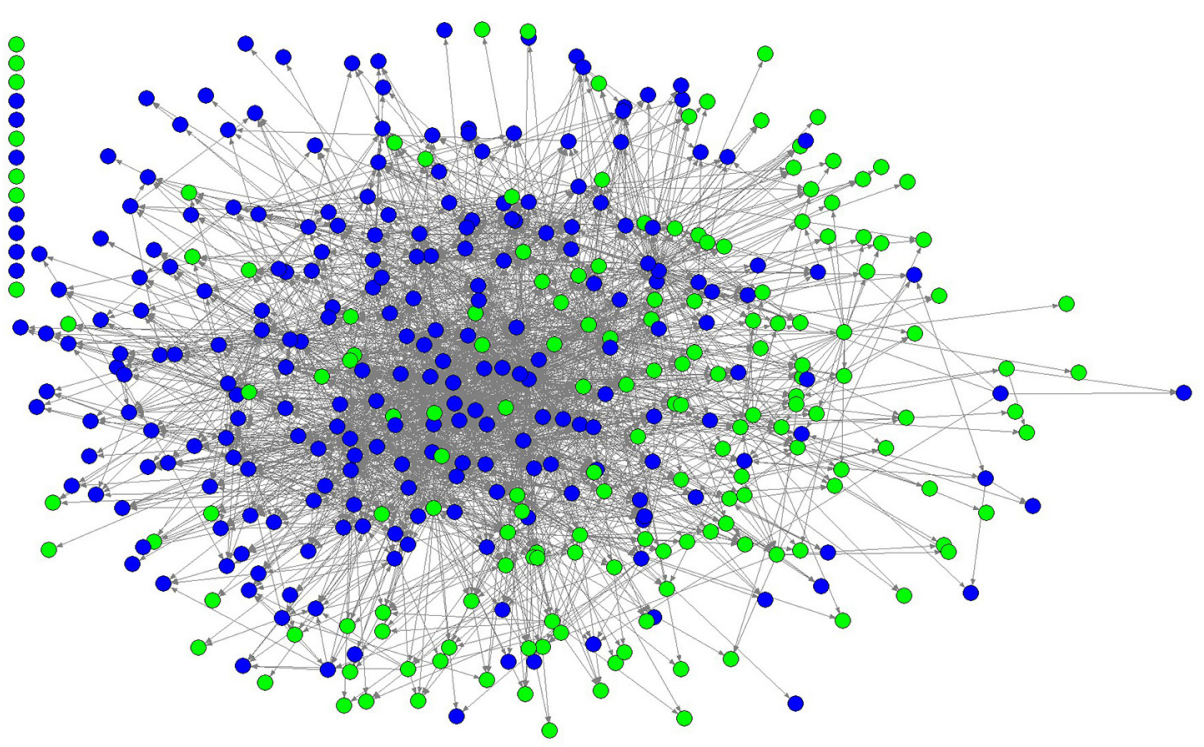

Figure 2.

Directed interaction network for most of the study population $(N=411$ nodes $)$
Notes: The 14 unconnected individuals in the top left did not take the survey, and no survey respondents indicated that they had interacted with them. Blue nodes are the scientists that had physical offices in any of the three HIPRI buildings. Green nodes are the scientists that are off-site or located in buildings that are elsewhere on the three university campuses, or offcampus but within the city. The network visualization was done using a spring-embedding with node repulsion (otherwise some nodes would be too close together making the map hard to read) algorithm that iteratively fits nodes on the graph such that those with shorter geodesics (path lengths) are located closer together. An effect of using this approach is that nodes with higher centrality tend to be in the center of the graph and those with lower centrality tend to be on the periphery (Figure 2)

(1) The people I work with treat me well.

(2) Communications seem good within HIPRI.

(3) Overall, I am satisfied with my job.

The computed interitem correlations or covariances showed that the four survey items combined to form a scale with a reasonably strong Cronbach's alpha coefficient ( $\alpha=0.76)$. Preliminary analysis showed that there was a significant difference in the mean SOC scores for individuals collocated at HIPRI compared to those who were off-site or not collocated as shown in Figure 3. The factor analyses were done using the Stata 16 MP statistical software (StataCorp, 2019).

The spatial proximity or colocation IV ("Has office at HIPRI") was generated from HIPRI internal records on office assignments and building locations which enabled us to determine whether an individual had an office or workspace assignment in any of the three HIPRI buildings at the research complex.

The models also included variables that controlled for gender ("Sex") given that the HIPRI population was skewed toward men (58\% male) and organizational affiliation ("Medical school affiliation") as $60 \%$ of the population had a medical school appointment. 


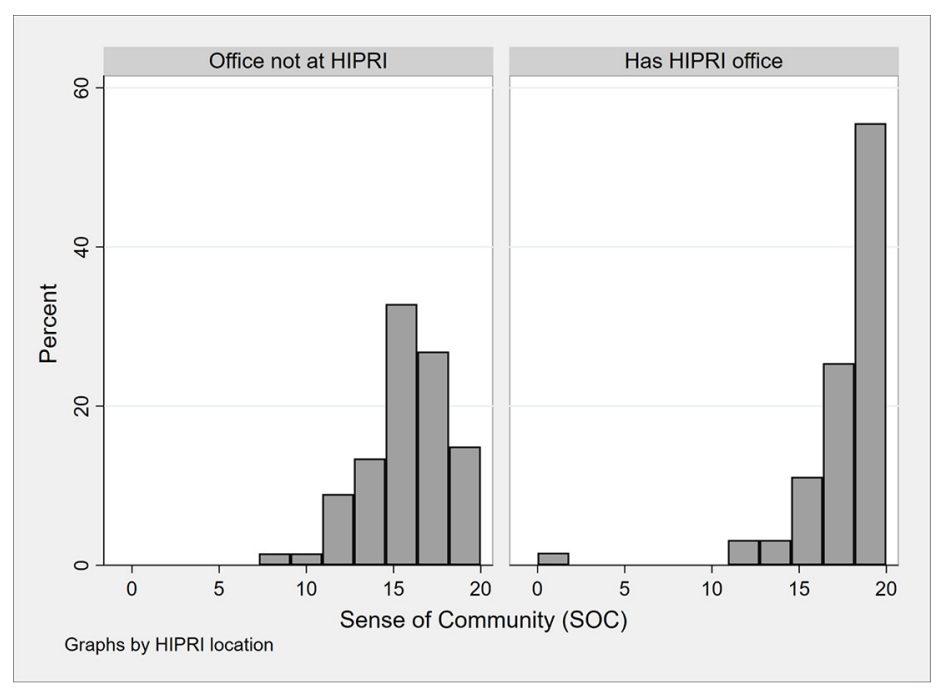

Notes: The mean responses for the two groups are 15.91 and 17.92, respectively, and the difference between the means is significant $(p<0.001)$
Overcoming the liability of distance

281

Figure 3.

Histograms for SOC by a) those who were off-site or located elsewhere at the university or in the city (left) and b) those who were collocated at HIPRI (right)

Finally, the individual's job category was controlled for using a 4-level categorical variable ("Job category") that mapped scientists across three tracks (tenure-track, research and clinical). Therefore, an assistant scientist and a clinical Assistant Professor are both in the same job category even though the former is on the research track while the latter is on the clinical track.

\section{Statistical analysis}

Network autocorrelation means using classical significance tests may yield misleading results as the standard formulas for computing standard errors and performing inferential tests assume that the observations are independent. Therefore, separate node-level network regression models were run for each DV (normalized network centralities) using the UCINET 6 SNA software (Borgatti et al., 2002). The node-level regressions use "bootstrapping" and permutations to calculate sampling distributions of statistics from the observed networks using random assignment across thousands of trials $(N=10,000)$ assuming that the null hypotheses are true (Hanneman and Riddle, 2005b, Borgatti et al., 2013). The basic linear regression model is defined as:

$$
N E T=\beta_{0}+\beta_{1} S O C+\beta_{2} L O C+\beta_{3} S E X+\beta_{4} M E D+\beta_{5} J O B+\hat{e}
$$

where:

NET = Network centrality (normalized degree, $A R D$, normalized betweenness);

SOC = sense of community;

LOC = has office at HIPRI;

SEX = sex;

MED = medical school affiliation; and

$\mathrm{JOB}=$ job category. 
JCRE 24,4

282
The standard errors and significance are estimated using the random permutations $(N=10,000)$ approach to constructing the sampling distributions of the $R$-squared and slope coefficients (Hanneman and Riddle, 2005b, Borgatti et al., 2013). While not reported here, for each of the three DVs separate models were run for the IVs (or predictors) and controls before combining them to gain a better understanding of the behavior of the IVs in the presence of the controls. The IVs behaved similarly with and without the controls. The results section that follows thus focuses on the full models that combine the IVs and controls.

\section{Results}

The results for the node-level network regression models with random permutations $(N=$ $10,000)$ are shown in Table 5 . Note that the overall job category variable was not significant in any of the models. In the interest of simplicity, the term "colocation" is used henceforth in contrast to the interchangeable use of the term and "proximity" in previous sections.

$\mathrm{SOC}$ is positively and significantly correlated with normalized degree (Model 1, $\beta=0.004$, $p<0.05$ ) and average reciprocal distance or $A R D$ (Model 2, $\beta=0.006, p<0.05$ ). However, the relationship between SOC and normalized betweenness (Model 3, $\beta=0.001$, n.s.) is not significant. Similarly, spatial colocation or having an office is positively and significantly associated with normalized degree (Model 1, $\beta=0.045, p<0.001$ ) and $A R D$ (Model 2, $\beta=$ $0.051, p<0.001$ ), but not with normalized betweenness (Model 3, $\beta=0.009, p<0.1$ ). For the network dimensions of interest in this study, the results suggest that spatial colocation and SOC have significant associations with connectedness (normalized degree) and reachability $(A R D)$ but have no significant correlations with brokerage (normalized betweenness).

The regression coefficients for both spatial colocation and SOC are larger for ARD than they are for normalized degree, suggesting that having an office and SOC have an impact of larger magnitude for reachability than they do for connectedness. However, the two IVs and controls are not reliable predictors of normalized betweenness based on the overall significance test for Model 3 ( $p=0.094)$. More specifically, the models show that sex and medical school affiliation do not have a statistically significant relationship with any of the three DVs in the study, and hence the network dimensions of connectedness, reachability and brokerage. With respect to job category, individuals at the full level have larger

\begin{tabular}{lccc}
\hline & Model 1 & Model 2 & \multicolumn{1}{c}{ Model 3} \\
Nariables & NDEG & ARD & \multicolumn{1}{c}{ NBET } \\
\hline SOC & $0.004^{*}(0.002)$ & $0.006^{*}(0.002)$ & $0.001(0.001)$ \\
Has office at HIPRI & $0.047^{* * *(0.011)}$ & $0.054^{* * *}(0.014)$ & $0.009+(0.005)$ \\
Sex & $-0.015(0.010)$ & $-0.023+(0.012)$ & $-0.002(0.005)$ \\
Medical school affiliation & $-0.006(0.012)$ & $-0.006(0.014)$ & $-0.001(0.006)$ \\
Job category (reference $=$ Assistant level) & & & $0.005(0.006)$ \\
Associate level & $0.019(0.013)$ & $0.013(0.016)$ & $0.013^{* *}(0.006)$ \\
Full level & $0.033^{* *}(0.012)$ & $0.021(0.014)$ & $-0.008(0.008)$ \\
Fellow/Investigator/Lecturer/other & $-0.023(0.016)$ & $-0.035(0.020)$ & $-0.015(0.014)$ \\
Constant & $-0.020(0.029)$ & $0.332(0.035)$ & $1.794+$ \\
Overall model $(F$-stat) & $5.635^{* * *}$ & $5.551^{* *}$ & 130 \\
Observations & 130 & 130 & 0.093 \\
$R^{2}$ & 0.244 & 0.242 & 0.041 \\
Adjusted $R^{2}$ & 0.201 & 0.198 &
\end{tabular}

Notes: Standard errors in parentheses, $* * * p<0.001, * * p<0.01, * p<0.05$ and $+p<0.1$
Table 5.

Results for the permutation-based node-level regression models of the associations between network centrality and SOC and spatial colocation (having an office at HIPRI) 
normalized degree and normalized betweenness centralities (Models 1 and 3) than those at the assistant level, implying that those at the full level have more network connectedness and brokerage potential than those at the assistant level who their juniors. However, recall that the job category variable does not have an overall statistically significant relationship with any of the three DVs or network centralities.

\section{Discussion}

This exploratory study demonstrates that there are positive and significant associations between network connectedness and reachability, and SOC and having an office or physical presence at the institute (spatial colocation). The study findings suggest that, as a psychological, cognitive and nonspatial construct, SOC is an important factor to consider in the absence of spatial colocation (or the liabilities of not having an office) in the workplace. The links between SOC and social networks have practical implications for large organizations where the imperative for building a collaborative organizational culture may be undermined by the infeasibility or impracticality of spatial colocation for all employees (Olson et al., 2002). That is, it may be neither practical nor feasible to provide offices or workspaces for all employees in some organizations. Workplace interventions based on the SOC construct could conceivably be used to engender the requisite common ground among groups and teams that are expected to collaborate remotely or over distance (Olson and Olson, 2000). There is evidence that the rapid shift to remote work for formerly co-located workers during the pandemic has led to a deterioration of intraorganizational collaboration networks in some organizations (Yang et al., 2021). Intentional SOC interventions targeted at physical communities, such as the facilitation of face-to-face meetings among neighbors (O'Connor, 2013) could potentially be translated to virtual settings assuming that there are suitable analogues or equivalents.

Designers of these potential workplace interventions could also consider the research that has been done with respect to: SOC in virtual communities (Blanchard and Markus, 2002; Blanchard and Markus, 2004; Blanchard, 2008), and; the links between, social interactions, social networks and SOC in virtual or online education (Rovai, 2002; Dawson, 2006; Dawson, 2008; Seckman, 2014). For example, the first line of inquiry has demonstrated that individuals in virtual communities could experience a sense of virtual community that is similar to the SOC found in geographically-bound communities (Blanchard and Markus, 2002). The second line of inquiry has shown that not only do actors with higher frequencies of online communication interactions have stronger levels of SOC (Dawson, 2006) but also that normalized degree centrality in the classroom network is positively correlated with an actor's reported SOC (Dawson, 2008). On the whole, this research makes it clear that where physical communities can organically develop SOC due to spatial colocation, online communities need greater intentionality in terms of fostering the communications and social interactions critical to building or facilitating SOC (Rovai, 2002). In part, this entails careful translation of the physical correlates of SOC at the focal level of analysis to their virtual equivalents. For example, participation in a neighborhood association has been found to be predictive of SOC (Long and Perkins, 2007). A virtual analogue of the neighborhood association could be created on hyperlocal social networking sites such as Nextdoor. At the organizational level, physical activity has been found to moderate SOC and employee vigor in the workplace (Scotto di Luzio et al., 2019). An organization could explore using a virtual, interactive fitness program to facilitate SOC among its employees that are working from home.

The study findings on the significant association between SOC and network position merit further study in the present-day context of work-from-home mandates in the USA and

\section{Overcoming the liability of distance}


JCRE 24,4

elsewhere in the world due to the COVID-19 pandemic. Under these mandates, most nonessential workers are expected to work from home and are, thus not afforded the benefits and affordances of spatial colocation such as with respect to the formation and maintenance of social ties and networks (Small and Adler, 2019; Doreian and Conti, 2012). This is important because the position or centrality of individuals in an organization or collaboration network is correlated with their performance (Sparrowe et al., 2001; Abbasi et al., 2011; Bordons et al., 2015). Further highlighting the importance of the association between SOC and network position, a recent study showed that psychological SOC had higher associations with network measures than the Big Five personality traits (Maya-Jariego et al., 2020). From an organizational perspective, workplace interventions aimed at fostering SOC have a higher likelihood of success than those attempting to modify or change individuals' personalities.

There was no significant association between network brokerage, and SOC and spatial colocation or having an office. This implies that SOC which is a cognitive or psychological component of social capital is less a function of whether an individual straddles the only paths between pairs of actors (brokerage), but rather is more associated with the ease with which the individual can reach and be reached by others in the network (connectedness and reachability). The study findings, therefore, contribute to our understanding of the links between network position and social capital, and to the debate on the relative importance of social cohesion (connectedness and reachability) and brokerage (Lambiotte and Panzarasa, 2009; Burt, 2000).

\section{Limitations}

The cross-sectional nature of the study data means that it was not possible to explore causal mechanisms with respect the links between SOC and network centrality, and the extent to which, for example, the mechanisms were a function of differences between off- and on-site HIPRI scientists. Longitudinal data would have enabled us to estimate pre-/post-intervention difference-in-difference models where the physical relocation to HIPRI would have been treated as the intervention with the on-site (physical presence) scientists as the treatment group and the off-site scientists as the control group. Future studies could focus on generating the types of longitudinal data that would enable causal analyses as well as the temporal dynamics between spatial colocation or having an office, SOC and network position.

\section{Future directions}

The SOC construct could potentially be used to create interventions that support collaborative organizations and workplaces in the context of employees working remotely (or hybrids of in-person and remote) during the COVID-19 pandemic. The importance of the workplace in fostering SOC for working adults cannot be understated (Klein and D'Aunno, 1986). For many, working during the pandemic has translated to mainly remote work which while it has advantages such as no commuting time also has the potential for the erosion of SOC in organizations and workplaces. This is at a time when SOC could help mitigate some of the isolating effects of working away from peers and the reduction of social contacts for working adults.

From a research perspective, there is a need for rapid SOC studies across workplaces in different organizational settings and including arrangements that are currently hybrid setups where essential employees may have to be in the physical workplace while the nonessential employees are working remotely. From a practice perspective, there is sufficient knowledge about the factors that are associated with building SOC in online communities to enable the creation of frameworks and protocols to guide workplace 
managers and organizational leaders in the translation of best practices from the physical workplace to the virtual workplace.

\section{Notes}

1. The list of interaction partners was generated using a combination of fixed list selection and expanding selection methods (Knoke and Yang, 2008a. Data collection. Social Network Analysis. Los Angeles: SAGE Publications, Inc.). The fixed list selection was based on the listing of all HIPRI scientists minus the focal actor. For the expanding selection, respondents could nominate up to 10 additional interaction partners who did not appear on the fixed list. In this study, however, only the network data from the fixed list selection is used for better boundary specification.

2. Examples of work interactions include regularly chatting in the break/coffee area, working on the same grant or contract, co-authoring a publication, co-patenting a discovery or invention, exchanging ideas during chance or unscripted encounters, or project management and other administrative tasks.

\section{References}

Abbasi, A., Altmann, J. and Hossain, L. (2011), "Identifying the effects of co-authorship networks on the performance of scholars: a correlation and regression analysis of performance measures and social network analysis measures", Journal of Informetrics, Vol. 5 No. 4, pp. 594-607.

Allen, T.J. (1977), Managing the Flow of Technology: Technology Transfer and the Dissemination of Technological Information within the R\&D Organization, Cambridge, MA, MIT Press.

Allen, T.J. (2007), "Architecture and communication among product development engineers", Califormia Management Review, Vol. 49 No. 2, pp. 23-41.

Allen, T.J. and Fustfeld, A.R. (1975), "Research laboratory architecture and the structuring of communications", R\&D Management, Vol. 5 No. 2, pp. 153-164.

Allen, T.J. and Henn, G. (2007), The Organization and Architecture of Innovation: Managing the Flow of Technology, Burlington, MA, Butterworth-Heinemann.

Appel-Meulenbroek, R. (2009), "Knowledge sharing in research buildings and about their design", in Koch, D., Marcus, L. and Steen, J. (Eds), 7th International Space Syntax Symposium, 2009 Stockholm. Stockholm, KTH.

Baumann, C.E. and Boutellier, R. (2012), "Chance encounters: where do they take place and what is the benefit?”, 2012 Kidmore End. Academic Conferences International Limited, pp. 48-XIX.

Baumann, C.E., Zoller, F. and Boutellier, R. (2012), "Fostering creativity and innovation: spheres of interaction influence chance encounters", 2012 Reading. Academic Conferences International Limited, pp. 190-XII.

Blanchard, A.L. (2008), "Testing a model of sense of virtual community", Computers in Human Behavior, Vol. 24 No. 5, pp. 2107-2123.

Blanchard, A.L. and Markus, M.L. (2002), "Sense of virtual community - maintaining the experience of belonging", Proceedings of the 35th Annual HI International Conference on System Sciences, 10-10 Jan. 2002, pp. 3566-3575.

Blanchard, A.L. and Markus, M.L. (2004), "The experienced 'sense' of a virtual community: characteristics and processes”, Database for Advances in Information Systems, Vol. 35.No. 1, pp. 65-79.

Bordons, M., Aparicio, J., González-Albo, B. and Díaz-Faes, A.A. (2015), "The relationship between the research performance of scientists and their position in co-authorship networks in three fields", Journal of Informetrics, Vol. 9 No. 1, pp. 135-144.
Overcoming
the liability of
distance

285 
JCRE 24,4

Borgatti, S.P. (2002), NetDraw: Graph Visualization Software, Harvard, Analytic Technologies.

Borgatti, S.P. and Foster, P.C. (2003), "The network paradigm in organizational research: a review and typology", Journal of Management, Vol. 29 No. 6, pp. 991-1013.

Borgatti, S.P., Everett, M.G. and Freeman, L.C. (2002), Ucinet 6 for Windows: Software for Social Network Analysis, Harvard, Analytic Technologies.

Borgatti, S.P., Everett, M.G. and Johnson, J.C. (2013), Analyzing Social Networks, Thousand Oaks, Calif.; London, SAGE Publications.

Borgatti, S.P., Mehra, A., Brass, D.J. and Labianca, G. (2009), “Network analysis in the social sciences”, Science, Vol. 323 No. 5916, pp. 892-895.

Boyd, N.M. and Nowell, B. (2013), "Psychological sense of community: a new construct for the field of management”, Journal of Management Inquiry, Vol. 23 No. 2, pp. 107-122.

Breiger, R.L. (2004), "The analysis of social networks", in Hardy, M. and Bryman, A. (Eds), Handbook of Data Analysis, London, SAGE Publications.

Brown, M.G. (2008), "Proximity and collaboration: measuring workplace configuration", Journal of Corporate Real Estate, Vol. 10. No. 1, pp. 5-26.

Burt, R.S. (1992), Structural Holes: The Social Structure of Competition, Cambridge, Mass., Harvard University Press.

Burt, R.S. (2000), "The network structure of social capital", Research in Organizational Behavior, Vol. 22, pp. 345-423.

Burt, R.S. (2004), "Structural holes and good ideas", American Journal of Sociology, Vol. 110 No. 2, pp. 349-399.

Calabrese, F., Smoreda, Z., Blondel, V.D. and Ratti, C. (2011), "Interplay between telecommunications and face-to-face interactions: a study using mobile phone data", Plos One, Vol. 6 No. 7 , p. e20814.

Coleman, J.S. (1988), "Social capital in the creation of human capital", American Journal of Sociology, Vol. 94, (Supplement: Organizations and Institutions: Sociological and Economic Approaches to the Analysis of Social Structure) pp. S95-S120.

Cranford, S. (2020), "Zoom fatigue, hyperfocus, and entropy of thought", Matter, Vol. 3 No. 3, pp. 587-589.

Cummings, J.J. and Bailenson, J.N. (2016), "How immersive is enough? A meta-analysis of the effect of immersive technology on user presence", Media Psychology, Vol. 19 No. 2, pp. 272-309.

Davis, G.F. (2007), "Networks in and around organizations", in Scott, W.R. and Davis, G.F. (Eds), Organizations and Organizing: rational, Natural, and Open System Perspectives, Upper Saddle River, N.J., Pearson Prentice Hall.

Dawson, S. (2006), "A study of the relationship between student communication interaction and sense of community", The Internet and Higher Education, Vol. 9 No. 3, pp. 153-162.

Dawson, S. (2008), "A study of the relationship between student social networks and sense of community”, Journal of Educational Technology and Society, Vol. 11. No. 3, pp. 224-22n/a.

Doreian, P. and Conti, N. (2012), "Social context, spatial structure and social network structure", Social Networks, Vol. 34 No. 1, pp. 32-46.

Fosslien, L. and Duffy, M.W. (2020), How to Combat Zoom Fatigue, Harvard Business Review.

Freeman, L.C. (1977), "A set of measures of centrality based on betweenness", Sociometry, Vol. 40 No. 1, pp. $35-41$.

Gilbert, B. (2020), "All your friends are using zoom, the video-chat app that is suddenly dominating competition from google and microsoft", available at: www.businessinsider.com/zoom-videoeverywhere-google-hangouts-skype-2020-3?op=1 (accessed 12 October 2020). 
Hanneman, R.A. and Riddle, M. (2005a), "Connection and distance”, Introduction to Social Network Methods, Riverside, CA, University of CA, Riverside.

Hanneman, R.A. and Riddle, M. (2005b), "Some statistical tools", Introduction to Social Network Methods, Riverside, CA, University of CA, Riverside.

Hanneman, R.A. and Riddle, M. (2014), "Concepts and measures for basic network analysis", in Scott, J. and Carrington, P.J. (Eds), The SAGE Handbook of Social Network Analysis, London, SAGE Publications Ltd.

Hoegl, M. and Proserpio, L. (2004), "Team member proximity and teamwork in innovative projects",

Overcoming the liability of distance Research Policy, Vol. 33 No. 8, pp. 1153-1165.

Huisman, M. and Steglich, C. (2008), "Treatment of non-response in longitudinal network studies", Social Networks, Vol. 30 No. 4, pp. 297-308.

Kabo, F., Hwang, Y., Levenstein, M. and Owen-Smith, J. (2015), "Shared paths to the lab: a sociospatial network analysis of collaboration", Environment and Behavior, Vol. 47 No. 1, pp. 57-84.

Kabo, F.W., Cotton-Nessler, N., Hwang, Y.H., Levenstein, M.C. and Owen-Smith, J. (2014), "Proximity effects on the dynamics and outcomes of scientific collaborations", Research Policy, Vol. 43 No. 9, pp. 1469-1485.

Klein, K.J. and D'Aunno, T.A. (1986), "Psychological sense of community in the workplace", Journal of Community Psychology, Vol. 14 No. 4, pp. 365-377.

Knoben, J. and Oerlemans, L.A.G. (2006), "Proximity and inter-organizational collaboration: a literature review", International Journal of Management Reviews, Vol. 8 No. 2, pp. 71-89.

Knoke, D. and Yang, S. (2008a), "Data collection", Social Network Analysis, Los Angeles, SAGE Publications, Inc.

Knoke, D. and Yang, S. (2008b), "Network fundamentals", Social Network Analysis, Los Angeles, SAGE Publications, Inc.

Lambiotte, R. and Panzarasa, P. (2009), "Communities, knowledge creation, and information diffusion”, Journal of Informetrics, Vol. 3 No. 3, pp. 180-190.

Lederberg, J. and Uncapher, K. (1989), Towards a National Collaboratory: Report of an Invitational Workshop at the Rockefeller University, 17-18 March 1989, National Science Foundation, Directorate for Computer and Information Science and Engineering.

Lee, K., Brownstein, J.S., Mills, R.G. and Kohane, I.S. (2010), "Does collocation inform the impact of collaboration?", PLoS ONE, Vol. 5 No. 12, p. e14279.

Leone Sciabolazza, V., Vacca, R., Kennelly Okraku, T. and Mccarty, C. (2017), "Detecting and analyzing research communities in longitudinal scientific networks", Plos One, Vol. 12 No. 8, p. e0182516.

Lin, N. (2001), Social Capital: A Theory of Social Structure and Action, Cambridge; New York, NY, Cambridge University Press.

Long, D.A. and Perkins, D.D. (2007), "Community social and place predictors of sense of community: a multilevel and longitudinal analysis", Journal of Community Psychology, Vol. 35 No. 5, pp. 563-581.

Mcmillan, D.W. and Chavis, D.M. (1986), "Sense of community: a definition and theory", Journal of Community Psychology, Vol. 14 No. 1, pp. 6-23.

Maya-Jariego, I., Letina, S. and González Tinoco, E. (2020), "Personal networks and psychological attributes: exploring individual differences in personality and sense of community and their relationship to the structure of personal networks", Network Science, Vol. 8 No. 2, pp. 168-188.

Mizruchi, M.S. and Marquis, C. (2006), "Egocentric, sociocentric, or dyadic?: identifying the appropriate level of analysis in the study of organizational networks", Social Networks, Vol. 28 No. 3, pp. $187-208$.

Morris, B. (2020), "Why does zoom exhaust you? Science has an answer", Wall Street Journal, 27 May 2020. 
JCRE 24,4

Nardi, B. and Whittaker, S. (2002), "The place of face-to-face communication in distributed work", in HINDS, P.J. and KIESLER, S. (Eds) Distributed Work, Cambridge, MA, Academic Press.

NATIONAL RESEARCH COUNCIL (1993), National Collaboratories: Applying Information Technology for Scientific Research, Washington, DC, National Academies Press.

O'CONNOR, B. (2013), "From isolation to community: exploratory study of a sense-of community intervention", Journal of Community Psychology, Vol. 41 No. 8, pp. 973-991.

Olson, G.M. and Olson, J.S. (2000), "Distance matters", Human-Computer Interaction, Vol. 15 Nos 2/3, pp. 139-178.

Olson, J.S., Teasley, S., Covi, L. and Olson, G. (2002), "The (currently) unique advantages of collocated work", in Hinds, P.J. and Kiesler, S. (Eds), Distributed Work, Cambridge, MA, Academic Press.

Penn, A., Desyllas, J. and Vaughan, L. (1999), "The space of innovation: interaction and communication in the work environment", Environment and Planning B: Planning and Design, Vol. 26 No. 2, pp. 193-218.

Peponis, J., Bafna, S., Bajaj, R., Bromberg, J., Congdon, C., Rashid, M., Warmels, S., Yan, Z. and Zimring, C. (2007), "Designing space to support knowledge work", Environment and Behavior, Vol. 39 No. 6, pp. 815-840.

Perkins, D.D. and Long, D.A. (2002), "Neighborhood sense of community and social capital", in Fisher, A.T., Sonn, C.C. and Bishop, B.J. (Eds), Psychological Sense of Community: Research, Applications, and Implications, Boston, MA, Springer US.

Podolny, J.M. (2001), "Networks as the pipes and prisms of the market", American Journal of Sociology, Vol. 107 No. 1, pp. 33-60.

Portes, A. (1998), "Social capital: its origins and applications in modern sociology", Annual Review of Sociology, Vol. 24 No. 1, pp. 1-24.

QUALTRICS (2017), Qualtrics. September, 2017 ed, Provo, UT, Qualtrics.

Rashid, M. (2013), “A study of the effects of colocation on office workers' perception”, Journal of Corporate Real Estate, Vol. 15 No. 2, pp. 98-116.

Rovai, A.P. (2002), "Building sense of community at a distance", The International Review of Research in Open and Distributed Learning, Vol. 3 No. 1.

Rung, A.L., Gaston, S., Robinson, W.T., Trapido, E.J. and Peters, E.S. (2017), "Untangling the disasterdepression knot: the role of social ties after deepwater horizon", Social Science and Medicine, Vol. 177, pp. 19-26.

Sailer, K. and Mcculloh, I. (2012), "Social networks and spatial configuration - how office layouts drive social interaction", Social Networks, Vol. 34 No. 1, pp. 47-58.

Sarason, S.B. (1974), The Psychological Sense of Community; Prospects for a Community Psychology, San Francisco, Jossey-Bass.

Schroeder, R., Steed, A., Axelsson, A.-S., Heldal, I., Abelin, Å., Wideström, J., Nilsson, A. and Slater, M. (2001), "Collaborating in networked immersive spaces: as good as being there together?", Computers and Graphics, Vol. 25 No. 5, pp. 781-788.

Scotto DI Luzio, S., Isoard-Gautheur, S., Ginoux, C. and Sarrazin, P. (2019), "Exploring the relationship between sense of community and vigor in workplace community: the role of needs satisfaction and physical activity", Journal of Community Psychology, Vol. 47 No. 6, pp. 1419-1432.

Seckman, C.A. (2014), "Perceived sense of community, cognitive engagement, and learning outcomes among undergraduate nursing students enrolled in an internet-based learning course", CIN: Computers, Informatics, Nursing, Vol. 32. No. 10.

Sengupta, N.K., Luyten, N., Greaves, L.M., Osborne, D., Robertson, A., Armstrong, G. and Sibley, C.G. (2013), "Sense of community in New Zealand neighbourhoods: a multi-level model predicting social capital", New Zealand Journal of Psychology, Vol. 42, p. 36. 
Serrato, M. and Wineman, J. ( 1999), "Spatial and communication patterns in research and development facilities”, 2nd International Space Syntax Symposium, March/April 1999 1999. Brasilia, Brazil, pp. 11.1-11.8.

Sherr, I. (2020), "Microsoft's skype sees massive increase in usage as coronavirus spreads [online]", available at: www.cnet.com/news/microsofts-skype-sees-massive-increase-in-usage-as-coronavirusspreads/ (accessed 12 October 2020).

Small, M.L. and Adler, L. (2019), "The role of space in the formation of social ties", Annual Review of Sociology, Vol. 45 No. 1, pp. 111-132.

Overcoming the liability of distance

Sparrowe, R.T., Liden, R.C., Wayne, S.J. and Kraimer, M.L. (2001), "Social networks and the performance of individuals and groups", The Academy of Management Journal, Vol. 44, No. 2, pp. 316-325.

STATACORP (2019), Stata Statistical Software: Release 16, College Station, TX, StataCorp LLC.

Stork, D. and Richards, W.D. (1992), Group and Organization Management, Vol. 17 No. 2, pp. 193-209.

Teasley, S. and Wolinsky, S. (2001), "Scientific collaborations at a distance", Science, Vol. 292 No. 5525, pp. 2254-2255.

Toker, U. and Gray, D.O. (2008), "Innovation spaces: workspace planning and innovation in US university research centers", Research Policy, Vol. 37 No. 2, pp. 309-329.

Wiederhold, B.K. (2020), "Connecting through technology during the coronavirus disease 2019 pandemic: avoiding 'zoom fatigue', Cyberpsychology, Behavior, and Social Networking, Vol. 23 No. 7, pp. 437-438.

Wineman, J., Hwang, Y., Kabo, F., Owen-Smith, J. and Davis, G. (2014), "Spatial layout, social structure and innovation in organizations", Environment and Planning B: Planning and Design, Vol. 41 No. 6.

Wineman, J., Kabo, F.W. and Davis, G.F. (2009), "Spatial and social networks in organizational innovation", Environment and Behavior, Vol. 41 No. 3, pp. 427-442.

Wood, L., Frank, L.D. and Giles-Corti, B. (2010), "Sense of community and its relationship with walking and neighborhood design", Social Science and Medicine, Vol. 70 No. 9, pp. 1381-1390.

Wulf, W.A. (1993), “The collaboratory opportunity”, Science, Vol. 261 No. 5123, pp. 854-855.

Yang, L., Holtz, D., Jaffe, S., Suri, S., Sinha, S., Weston, J., Joyce, C., Shah, N., Sherman, K., Hecht, B. and Teevan, J. (2021), "The effects of remote work on collaboration among information workers", Nature Human Behaviour.

Zhang, Z. and Zhang, J. (2017), "Perceived residential environment of neighborhood and subjective wellbeing among the elderly in China: a mediating role of sense of community", Journal of Environmental Psychology, Vol. 51, pp. 82-94.

\section{Further reading}

Freeman, L.C. (1978), “Centrality in social networks conceptual clarification”, Social Networks, Vol. 1 No. 3, pp. 215-239.

\section{Corresponding author}

Felichism Kabo can be contacted at: fkabo@umich.edu

For instructions on how to order reprints of this article, please visit our website: 